\title{
Isoform-specific and cell/tissue-dependent effects of p38 MAPKs in regulating inflammation and inflammation-associated oncogenesis
}

\author{
Jian-Zhong Qin ${ }^{1}$, Hong Xin ${ }^{1}$, Xiao-Mei Qi ${ }^{1}$, Guan Chen ${ }^{1,2, *}$ \\ ${ }^{1}$ Department of Pharmacology and Toxicology, Medical College of Wisconsin, Milwaukee, WI 53223, USA \\ ${ }^{2}$ Research Service, Clement J. Zablocki Veterans Affairs Medical Center, Milwaukee, WI 53295, USA \\ *Correspondence: gchen@mcw.edu (Guan Chen) \\ Academic Editor: Graham Pawelec \\ Submitted: 11 November 2021 Revised: 29 December 2021 Accepted: 29 December 2021 Published: 18 January 2022
}

\begin{abstract}
p38 MAPK (mitogen-activated protein kinases) family proteins $(\alpha, \beta, \gamma$ and $\delta$ ) are key inflammatory kinases and play an important role in relaying and processing intrinsic and extrinsic signals in response to inflammation, stress, and oncogene to regulate cell growth, cell death and cell transformation. Recent studies in genetic mouse models revealed that $\mathrm{p} 38 \alpha$ in epithelial cells mostly suppresses whereas in immune cells it promotes inflammation and inflammation-associated oncogenesis. On the contrary, p38 $\gamma$ and $\mathrm{p} 38 \delta$ signaling in immune and epithelial cells is both pro-inflammatory and oncogenic. This review summarizes recent discoveries in this field, discusses possible associated mechanisms, and highlights potentials of systemically targeting isoform-specific p38 MAPKs. Understanding of p38 MAPK isoform-specific and cell/tissue- and perhaps stage-dependent effects and their integrated regulated activity in inflammation and in inflammation-associated oncogenesis is essential for effectively targeting this group of kinases for therapeutic intervention.
\end{abstract}

Keywords: p38 MAPKs; Isoform-specific and cell/tissue-dependent effects; Inflammation; Inflammation-associated oncogenesis

\section{Introduction}

p38 mitogen-activated protein kinases (MAPKs) $(\alpha$, $\beta, \gamma$ and $\delta$ ) are encoded by four different genes in four different chromosomes [1]. p38 MAPKs are dualphosphorylated on tyrosine and threonine residues within a conserved Thr-Pro-Tyr (TPY) motif by MAPK kinase 3 (MKK3) and/or MKK6, which in turn phosphorylate a substrate typically containing a ST/P motif (Ser or Thr residue, followed by Pro [1]). p38 $\alpha$ and p $38 \beta$ phosphorylate more than 100 substrates [2], and many of them are not phosphorylated by $\mathrm{p} 38 \gamma$ and $\mathrm{p} 38 \delta$ that have specific and nonoverlapping substrates and are therefore called alternative p38 MAPKs [3-5]. Although distinct substrates may play a role in an isoform-specific effect of p38 MAPKs, how p38 MAPK family members signal via common and unique substrates are largely unknown $[2,4]$. We will review recent discoveries from genetic studies about isoform-specific and cell/tissue-dependent effects of p38 MAPKs in inflammation and in inflammation-associated oncogenesis and discuss potentials of targeting a specific p38 isoform in therapeutic intervention.

p38 $\alpha$ is expressed universally in all tissues and/or cells, whereas other $\mathrm{p} 38$ family proteins are only detectable in certain tissues and/or cells [1,2]. Although all p38 MAPKs can be activated similarly in response to inflammation, stress and oncogenic signaling, they can also be activated distinctively [1,2,6-9]. Oncogene RAS, for example, stimulates p $38 \alpha$ (also called p38) phosphorylation but increases RNA/protein levels of p38 $\gamma$ (and not other $\mathrm{p} 38$ MAPKs), indicating that $\mathrm{p} 38$ MAPKs are activated by Ras oncogene by an isoform-specific mechanism [6,7,10-12]. Furthermore, elevated p38 $\gamma$ gene expression was demonstrated in human breast, colon, and pancreatic cancers, which is correlated with decreased patient survival, indicating its potential roles in malignant development and progression in clinic [9,10,12-15]. In addition, treatment of mice with the inflammation stimulus dextran sulfate sodium (DSS) preferably stimulates p38 $\gamma$ phosphorylation (as compared to $\mathrm{p} 38 \alpha$ ) in intestinal epithelial tissues/cells [16], whereas $\mathrm{p} 38 \alpha$ (to a less extent for $\mathrm{p} 38 \delta$ ) is predominantly activated by lipopolysaccharide (LPS) [17] and tumor necrosis factor (TNF) [18]. In patients with chronic inflammation (arthritis), however, p38 $\alpha$ and p38 $\gamma$, but not other p38s, are both activated [19]. A distinct activationpattern of $\mathrm{p} 38$ family proteins by different stimuli may play an important role in their different biological outcomes and an elevated p38 $\gamma \mathrm{RNA} /$ protein in Ras-transformed cells and in cancers indicates its potential as a sustainable therapeutic target for pharmacological intervention.

p38 family MAPK proteins also differently activate their downstream substrates such as kinases and transcription factors $[2,4]$. Several kinases, including p38 regulated/activated kinase (PRAK), and mitogen-activated protein kinase-interacting kinase 1 (MNK1), are phosphorylated by $\mathrm{p} 38 \alpha$ and/or $\mathrm{p} 38 \beta$ in vitro and in cells, but not by other p38 isoforms, whereas MAP kinase-activated protein kinase 2 (MK2) is activated by all p38 family proteins $[1,4]$. Transcription factors myocyte enhancer factor $2 \mathrm{C}$ (MEF2C) and activating transcription factor-2 (ATF2) are activated by all p38 family proteins $[3,4]$. Although c-Jun is 
activated by $\mathrm{p} 38 \alpha$ and $\mathrm{p} 38 \gamma$, this occurs via distinct mechanism: c-Jun is activated by $\mathrm{p} 38 \alpha$ through phosphorylation of the AP-1 partner proteins Sap- $1 \alpha$ and ATF2 [1] but activated by $\mathrm{p} 38 \gamma$ via AP-1-dependent transcription [20-22]. The different effects of p38 family proteins on downstream kinases and transcription factors may play an important role in their isoform-specific and cell/tissue-dependent activities.

p38 $\gamma$ protein has a unique structure among p38 family proteins, which may determine its capacity to phosphorylate a specific substrate and to signal via a specific pathway through interacting with different proteins $[1,15$, 23,24]. Specifically, p38 $\gamma$ C-terminal contains a PDZbinding motif that interacts with PDZ-domain containing proteins including its substrate SAP90 [25] and its phosphatase protein tyrosine phosphatase H1 (PTPH1) [11,15]. Moreover, PDZ motif is required for $\mathrm{p} 38 \gamma$ to interact with c-Jun in cells [20], which may be important for $\mathrm{p} 38 \gamma$ to activate AP-1-dependent gene transcription, including cJun, matrix metalloproteinase (MMP9) [20], Nanog [21], and epidermal growth factor receptor (EGFR) [22]. Furthermore, p38 $\gamma$ depends on PDZ motif to bind, phosphorylate and activate PTPH1 [26], which is important for PTPH1 to catalyze EGFR dephosphorylation and to promote KRAS-dependent growth [22,27]. In addition, p38 $\gamma$ binds and/or phosphorylates several proliferative proteins, including DNA topoisomerase II $\alpha$ (Topo II $\alpha$ ) and estrogen receptor $\alpha(\mathrm{ER})$ in breast cancer [8,9], heat shock protein 90 (Hsp90) and $\beta$-catenin in colon cancer $[13,16]$, and glucose transporter 2 (Glut2) and phosphofructokinase-2/fructose2,6-bisphosphatase 3 (PFKFB3) in pancreatic cancer [12]. It is not known, however, if PDZ binding is directly and indirectly involved in $\mathrm{p} 38 \gamma$ interacting with this group of proliferative proteins. These results together indicate that $\mathrm{p} 38 \gamma$ may execute its oncogenic activity through interaction with other proliferative proteins dependent and independent of PDZ binding [28].

\section{Effects of p38 $\alpha / \beta$ knockout on inflammation and inflammation-associated oncogenesis}

Cell culture studies showed $\mathrm{p} 38 \alpha$ inhibits Ras proliferative activity in NIH3T3 fibroblasts by negative feedback in which transient transfection of oncogenic Ras (HRAS $^{G 61 L}$ ) stimulates phosphorylation of each member of the co-transfected $\mathrm{p} 38 \alpha$ pathway MKK6 (MAPK kinase 6), p38 $\alpha$, and PRAK (p38-related/activated protein kinase)/MAPK-activated protein kinase 2 (MK2), which in turn suppresses Ras proliferative response [6]. The $\mathrm{p} 38 \alpha$ suppressive activity on Ras oncogene was further demonstrated pharmacologically in intestinal epithelial cells (IEC) in which Ras-dependent soft-agar growth was increased by treatment with the $\mathrm{p} 38 \alpha / \beta$ inhibitor SB203586 [29]. Moreover, the $\mathrm{p} 38$ upstream activator MKK6 and down-stream kinase PRAK and MK2 were further shown to suppress Ras proliferative activity and/or Ras-induced transformation in different in vitro and in vivo systems [6,30-35], although recent MK2 knockout studies showed its promoting role in colitis-associated cancer [36]. These results together indicate that the $\mathrm{p} 38 \alpha$ pathway activities in target cells (fibroblasts and epithelial cells) are inhibitory to Ras proliferative activity and oncogenic transformation in cell culture [7] (Table 1, Ref. [12,16,34,37-64]).

Systemic effects of $\mathrm{p} 38 \alpha$ in inflammation and in inflammation-associated oncogenesis have been investigated by knockout $(\mathrm{KO})$ studies in mice. Because global $\mathrm{p} 38 \alpha \mathrm{KO}$ is embryonic lethal $[65,66]$, inducible and/or conditional p38 $\alpha$ KO was developed. Specific p $38 \alpha \mathrm{KO}$ in macrophages leads to changes in pro-inflammatory cytokines TNF, IL-6, and anti-inflammatory cytokine IL-10 in bone marrow-derived macrophages (BMDM) in a manner dependent of stimuli and of treatment time, which is blocked by IL-10 antibody, indicating a proinflammatory response [56]. Further, myeloid p38 $\alpha$ KO decreases colitis, inhibits colitis-associated cancer (CAC) [42], and prolongs survival of IL-10 $10^{-/}$mice, indicating that myeloid $\mathrm{p} 38 \alpha$ is pro-inflammatory and oncogenic [56]. A proinflammatory role of $\mathrm{p} 38 \alpha$ is also demonstrated by a decrease in 2,4-dinitrofluorobenzene (DNFB)-induced ear swelling in mice with $\mathrm{p} 38 \alpha \mathrm{KO}$ in dendritic cells (DCs) and in T cells, although myeloid-specific p38 $\alpha \mathrm{KO}$ had an opposite effect [48]. Moreover, p38 $\alpha$ KO in DCs inhibits dextran sodium sulfate (DSS)-induced colitis and attenuates DSS/azoxymethane (AOM)-induced CAC in association with decreased neutrophil infiltration and with changes in multiple cytokines in colon tissues [54], further indicating the pro-inflammatory and oncogenic role of $\mathrm{p} 38 \alpha$ in immune cells (Fig. 1). This conclusion is further supported by decreased lethality in mice after the treatment with lipopolysaccharide (LPS) in which p38 $\alpha$ is specifically deletion in macrophage in association with reduced blood levels of pro-inflammatory cytokines TNF, IL-12, and IL-18 [55]. Moreover, there is attenuated colitis and decreased inflammatory cytokine expression (after DSS) in mice with myeloid-specific p38 $\alpha$ KO [41]. Myeloid p38 $\alpha$ is also important for DSS-induced skin inflammation [46] and $\mathrm{p} 38 \alpha \mathrm{KO}$ in DCs, but not in macrophages or T cells, inhibits $\mathrm{T}_{H} 17$ differentiation, decreases IL-17 levels, and suppresses autoimmune inflammation [67]. In addition, inhibition of $\mathrm{p} 38 \alpha$ activity by expressing a dominant negative (dn) mutant in CD4 T cells decreases IL-17 expression and reduces the severity of allergic encephalomyelitis (EAE) [57]. Studies with a CRISPR-Cas9 screening of primary $T$ cells further showed that $\mathrm{p} 38 \alpha$ deletion increases the efficacy of mouse anti-tumor T cells $[50,68]$, thus demonstrating an oncogenic role of $\mathrm{p} 38 \alpha$ in T cells. A recent study further showed that $\mathrm{p} 38 \alpha$ activity (the phospho-p $38 \alpha /$ total p $38 \alpha$ ratio) in leukocytes isolated from the patient peripheral blood with metastatic melanoma is increased as compared to those without metastasis, and predicts decreased 


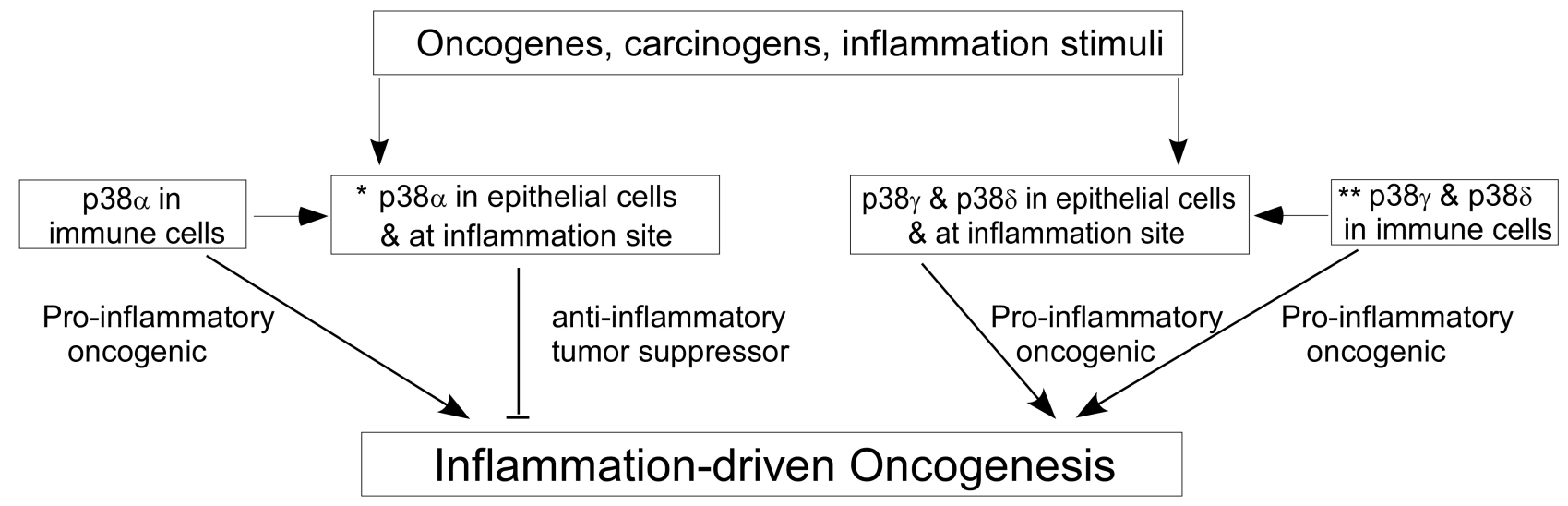

Fig. 1. p38 $(\alpha, \beta, \gamma$, and $\delta$ ) family proteins regulate inflammation and inflammation-associated oncogenesis by isoform-specific and cell/tissue-dependent mechanism. p38 $\alpha$ activity in immune cells is mostly proinflammatory and oncogenic while in epithelial cells (and other target cells such as MEFs) is anti-inflammatory and tumor suppressive. p $38 \gamma$ and $\mathrm{p} 38 \delta$ activity in immune and epithelial cells is both proinflammatory and oncogenic. * Biphasic effects of inducible p38 $\alpha \mathrm{KO}$ in intestinal epithelial cells and in lung epithelial projector cells, i.e., p38 $\alpha$ is a tumor suppressor in cancer initiation stage but is oncogenic in advanced stage likely via tumor-stromal interactions. No p $38 \beta$ studies on inflammation and/or cancer have been reported. ** Only studies of conditional p38 $\delta$ and combined $\mathrm{p} 38 \gamma / \mathrm{p} 38 \delta \mathrm{KO}$ in myeloid cells were reported.

patient survival, and that $\mathrm{p} 38 \alpha \mathrm{KO}$ specifically in fibroblasts attenuates lung metastasis of melanoma in mice [51]. Moreover, specific deletion of $\mathrm{p} 38 \alpha$ from fibroblasts also inhibits KRAS-induced lung tumorigenesis [52]. These results together indicate that $\mathrm{p} 38 \alpha$ activity in stromal cells (immune cells and fibroblasts) overall is pro-inflammatory and/or oncogenic [48,54,67] (Fig. 1) (Tables 1,2).

Studies with specific p $38 \alpha \mathrm{KO}$ in epithelial cells in which tumor develops, however, showed that $\mathrm{p} 38 \alpha$ is antiinflammatory with a tumor suppressor activity $[40,41,43$, 44,49]. Experiments in mice with intestinal epithelial cell (IEC)-specific $\mathrm{p} 38 \alpha \mathrm{KO}$, for example, showed increased IEC proliferation, enhanced colitis severity and/or colon tumorigenesis after the treatment with DSS \pm azoxymethane (AOM) as compared to control mice $[41,43,44]$. An increase in the carcinogen diethyl nitrosamine (DEN)induced liver tumorigenesis was also observed in mice with hepatic-specific p38 $\alpha$ KO [40,49]. Moreover, studies in H-Ras-transformed or immortalized fibroblasts showed increased in vivo xenograft formation of mouse embryonic fibroblasts (MEFs) lacking $\mathrm{p} 38 \alpha$ [38] and its activator MKK3 and MKK6 [34]. Moreover, experiments with inducible $\mathrm{p} 38 \alpha$ global knockout revealed that $\mathrm{p} 38 \alpha$ KO increases lung stem cell proliferation and KRASinduced lung tumorigenesis [37]. In addition, co-injection of $\mathrm{p} 38 \alpha$-deleted mesenchymal stem cells (MSCs) increases xenograft growth of human colon cancer cells in nude mice in association with enhanced angiogenesis [39]. However, inhibition of $\mathrm{p} 38 \alpha$ nuclear translocation by a peptide attenuates $\mathrm{AOM} / \mathrm{DSS}$-induced colon cancer, likely through targeting $\mathrm{p} 38 \alpha$ in multiple cell-types and tissues [69]. These results together indicate that $\mathrm{p} 38 \alpha$ activity in target cells (epithelial, fibroblasts) and in co-injected MSCs is anti-inflammatory and/or tumor-suppressive in response to carcinogen, inflammation stimulus and/or RAS oncogene (Fig. 1).

Recent studies further showed that inducible $\mathrm{p} 38 \alpha \mathrm{KO}$ at a late stage in intestinal epithelial cells (65 days after AOM/DSS administration to induce colon tumor) and in alveolar epithelial progenitor cells (20 weeks after induction of $\operatorname{KRAS}^{G 12 V}$ expression in lungs) decreases tumorigenesis, despite the initial increase in tumorigenesis in both tissues $[44,45]$. Mechanisms involved however are mostly unclear and may involve epithelial p38 $\alpha$ signaling interaction with stromal once tumor reaches a certain size $[52,70]$. This speculation is supported by the fact that $\mathrm{p} 38 \alpha$ silencing in pancreatic cancer cells inhibits the cell growth in vitro but increases the xenograft formation of the same cells in mice [71] and that $\mathrm{p} 38 \alpha$ in fibroblasts promotes lung metastasis of melanoma [51] and lung tumorigenesis [52]. These results indicate a stage-specific role of epithelial p38 $\alpha$ in tumorigenesis and metastasis likely through signaling interactions with stromal tissues. Although studies also showed a distinct role of $\mathrm{p} 38 \alpha$ vs $\mathrm{p} 38 \beta$ in cell survival and cell death $[71,72], \mathrm{p} 38 \beta$ is generally believed to be redundant and its global KO did not show major phenotypes [73]. These results together indicate that $\mathrm{p} 38 \alpha$ in epithelial cells has a dual role in oncogenesis, i.e., anti-inflammatory as a tumor suppressor at the tumor initiation but oncogenic once tumor is established or becomes metastatic (Fig. 1) (Tables 1,2).

\section{Effects of $p 38 \gamma / \delta$ knockout on inflammation and inflammation-associated oncogenesis}

Genetic studies showed that mice with global $\mathrm{p} 38 \gamma$ and/or $\mathrm{p} 38 \delta$ knockout are phenotypically nor- 
Table 1. Effects of knockout of p38 MAPKs on inflammation and inflammation-associated oncogenesis.

\begin{tabular}{|c|c|c|}
\hline p38 knockout (KO) & Major phenotype & Reference \\
\hline$-/-$ (inducible KO) & $\begin{array}{l}\text { increased lung tumorigenesis } \\
\text { (KRAS) }\end{array}$ & {$[37]$} \\
\hline$-/-(\mathrm{KO}$ in MEFs $)$ & $\begin{array}{l}\text { increased transformation by } \\
\text { Ras and other oncogenes }\end{array}$ & {$[38]$} \\
\hline$-/-$ (inducible KO in MSCs) & $\begin{array}{l}\text { increased xenograft growth co-injected with } \\
\text { p38 } \text {-deleted mesenchymal stromal cells } \\
\text { (MSCs) }\end{array}$ & [39] \\
\hline liver-specific KO & $\begin{array}{l}\text { increased liver tumorigenesis } \\
\text { (Den-induced) }\end{array}$ & {$[40]$} \\
\hline $\begin{array}{l}\text { IEC-specific KO } \\
\text { myeloid-specific KO }\end{array}$ & $\begin{array}{l}\text { increased colitis (DSS) } \\
\text { decreased colitis (DSS) }\end{array}$ & [41] \\
\hline myeloid-specific KO & $\begin{array}{l}\text { decreased colitis-associated tumorigenesis } \\
\text { (AOM/DSS) }\end{array}$ & {$[42]$} \\
\hline IEC-specific KO & $\begin{array}{l}\text { increased colitis and colitis-associated cancer } \\
(\mathrm{CAC})(\mathrm{AOM} / \mathrm{DSS})\end{array}$ & [43] \\
\hline IEC-specific KO* & $\begin{array}{l}\text { biphasic; increased colon tumorigenesis early } \\
\text { and decreased tumor growth later }\end{array}$ & {$[44]$} \\
\hline $\begin{array}{l}\text { Alveolar epithelial type II* } \\
\text { (AE II-specific KO) }\end{array}$ & $\begin{array}{l}\text { biphasic, increased tumorigenesis early } \\
\text { and decreased tumor formation later (KRAS) }\end{array}$ & {$[45]$} \\
\hline myeloid-specific KO & $\begin{array}{l}\text { decreased skin inflammation to SDS } \\
\text { increase skin inflammation to UVB } \\
\text { increased skin inflammation to TPA }\end{array}$ & {$[46]$} \\
\hline $\begin{array}{l}\text { keratinocyte specific KO } \\
\text { DC specific KO }\end{array}$ & $\begin{array}{l}\text { decreased skin inflammation to UVB } \\
\text { no effect on skin inflammation to UVB }\end{array}$ & [45] \\
\hline $\begin{array}{l}\text { keratinocyte specific } \mathrm{KO} \\
\text { myeloid specific KO } \\
\text { DC specific KO } \\
\text { T cell specific KO }\end{array}$ & $\begin{array}{l}\text { increased skin inflammation to LPS/TPA } \\
\text { increased skin inflammation to LPS/TPA } \\
\text { decreased skin inflammation to LPS/TPA } \\
\text { decreased skin inflammation to LPS/TPA }\end{array}$ & [48] \\
\hline Hepatic-specific KO & $\begin{array}{l}\text { increased liver tumorigenesis } \\
\text { (Den-induced) }\end{array}$ & [49] \\
\hline $\begin{array}{l}\text { T cell specific KO } \\
\text { (CRISPR-Cas9) }\end{array}$ & $\begin{array}{l}\text { increased adoptive immunotherapy } \\
\text { increased anti-tumor activity of } \mathrm{T} \text { cells }\end{array}$ & {$[50]$} \\
\hline$-/-$ (inducible) $\&$ & decreased lung metastatic of melanoma & {$[51]$} \\
\hline Fibroblasts-specific KO & decreased lung metastatic of melanoma & \\
\hline Fibroblast-specific KO & decreased lung tumorigenesis (KRAS model) & {$[52]$} \\
\hline DC-specific KO & $\begin{array}{l}\text { decreased } \mathrm{T}_{H}-17 \text { cell differentiation and } \\
\text { decreased IL-23/IL-6 expression }\end{array}$ & {$[53]$} \\
\hline DC-specific KO & $\begin{array}{l}\text { decreased colitis/colon tumors (AOM/DSS), } \\
\text { increased JNK, IL-10, IFN- } \gamma \text { and } \\
\text { decreased IL-6, TNF, IL-1 } \beta \text {, and IL-17 }\end{array}$ & {$[54]$} \\
\hline Macrophage specific KO & decreased LPS-induced TNF $\alpha$, IL-12 and IL-18 & {$[55]$} \\
\hline Macrophage specific KO & decreased colitis in IL- $10^{-/-}$mice & {$[56]$} \\
\hline Keratinocyte-specific KO & decreased skin inflammation (to UVB) & \\
\hline MKK3/6-/- in CD4T cells & decreased IL-17 & {$[57]$} \\
\hline p38 $\alpha$ dn Tg in CD4T cells & decreased IL-17 & \\
\hline $\begin{array}{l}\text { MKK } 3 / 6^{-/-} \text {in MEFs } \\
\text { p38 } \beta\end{array}$ & $\begin{array}{l}\text { increased xenograft in immortalized cells } \\
\text { No studies reported }\end{array}$ & {$[34]$} \\
\hline
\end{tabular}


Table 1. Continued.

\begin{tabular}{|c|c|c|}
\hline p38 knockout (KO) & Major phenotype & Reference \\
\hline \multicolumn{3}{|l|}{ p38 $\gamma$} \\
\hline$-1-$ & $\begin{array}{l}\text { decreased TNF } \alpha \text {, IL- } \beta \text { and IL-10 } \\
\text { in response to LPS }\end{array}$ & [58] \\
\hline$-/-* *$ & $\begin{array}{l}\text { decreased colon tumorigenesis } \\
\text { when combined with } \mathrm{p} 38 \delta^{-/-}(\mathrm{AOM} / \mathrm{DSS})\end{array}$ & [59] \\
\hline$-/-* *$ & $\begin{array}{l}\text { decreased skin tumorigenesis } \\
\text { when combined with } \mathrm{p} 38 \delta^{-/-} \text {(DMBA/TPA) }\end{array}$ & [60] \\
\hline$-/-$ & 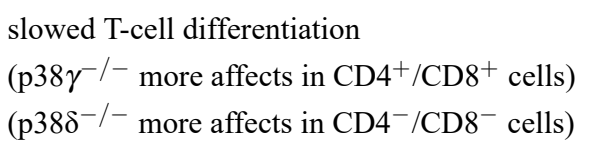 & {$[61]$} \\
\hline IEC-specific KO & $\begin{array}{l}\text { decreased colitis and CAC } \\
\text { (AOM/DSS model) }\end{array}$ & [16] \\
\hline Hepatic-specific KO & $\begin{array}{l}\text { Decreased liver tumorigenesis } \\
\text { (Den model) }\end{array}$ & [62] \\
\hline pancreas-specific KO & $\begin{array}{l}\text { Decreased pancreatic tumorigenesis } \\
\text { (KPC model) }\end{array}$ & [12] \\
\hline \multicolumn{3}{|l|}{ p38ס } \\
\hline$-1-$ & $\begin{array}{l}\text { decreased skin tumorigenesis } \\
\text { (DMBA model) }\end{array}$ & {$[63]$} \\
\hline$-/-* *$ & $\begin{array}{l}\text { decreased colon tumorigenesis } \\
\text { When combined with } \mathrm{p} 38 \gamma^{-/-} \\
\text {(AOM/DSS model) }\end{array}$ & [59] \\
\hline$-/-* *$ & $\begin{array}{l}\text { decreased skin tumorigenesis } \\
\text { when combined with } \mathrm{p} 38 \gamma^{-/-}(\mathrm{DMBA} / \mathrm{TPA})\end{array}$ & {$[60]$} \\
\hline$-1-$ & $\begin{array}{l}\text { decreased mammary tumorigenesis } \\
\text { (PyMT model) }\end{array}$ & [64] \\
\hline
\end{tabular}

The global knockout is indicated by a sign "-/-”, whereas conditional knockout (KO) is shown as cell/tissue-specific KO through the Cre recombinase technology. Tumors were induced by transgenic expression of the indicated oncogene and/or by treatment of mice with the indicated carcinogen \pm inflammation stimuli (please see details in the indicated references). *indicates a biphasic effect with enhanced tumorigenesis by inducible p38 $\alpha$ conditional KO during tumor initiation and with decreased tumor growth and/or metastasis after tumor established, and ${ }^{* *}$ shows similar phenotypes in $\mathrm{p} 38 \gamma \mathrm{KO}$ and $\mathrm{p} 38 \delta \mathrm{KO}$ mice, which is more substantial in their double KO mice. Effects of p38 $\gamma$ in experimental and clinic cancer were recently reviewed [74] and results from this table are summarized in Table 2.

Table 2. Summary of p38 MAPKs in inflammation and cancer.

\begin{tabular}{|c|c|c|c|c|c|c|c|c|c|}
\hline \multirow[b]{2}{*}{ Knockout } & \multicolumn{2}{|c|}{ Pro-inflammatory } & \multicolumn{2}{|c|}{ Anti-inflammatory } & \multirow[t]{2}{*}{ Tumor-suppressive } & \multicolumn{2}{|r|}{ Oncogenic } & Oncogenic & \multirow{2}{*}{ Others } \\
\hline & Epithelia & 1 Immune cel & Epithel & 1 Immune cel & & Epithe & elial Immun & Fibroblast & \\
\hline $\mathrm{p} 38 \alpha$ & & $\mathbf{X}^{*}$ & $\mathbf{X}$ & $\mathbf{X}^{*}$ & $\mathbf{X}$ & & $\mathrm{X}$ & $\mathbf{X}$ & \\
\hline $\mathrm{p} 38 \beta$ & & & & & & & & & $?$ \\
\hline $\mathrm{p} 38 \gamma$ & $\mathbf{X}$ & $\mathbf{X}$ & & & & $\mathbf{X}$ & & & \\
\hline $\mathrm{p} 38 \delta$ & $\mathbf{X}$ & $\mathbf{X}$ & & & & $\mathbf{X}$ & & & \\
\hline
\end{tabular}

*Response differs in a stimulus- and cell/tissue-specific manner.

mal, which however results in a decrease in multiple cytokines in response to lipopolysaccharide [LPS, a toll-like receptor 4 (TLR4) ligand] in bone marrowderived macrophages (BMDM) [58,75]. Although global p38 $\gamma$ knockout alone has no significant effect on 7,12-dimethylbenz(a)anthracene (DMBA)/tetradecanoylphorbol-13-acetate (TPA)-induced skin tumorigenesis as compared with wild-type (WT) mice, there is attenuated tumorigenesis in $\mathrm{p} 38 \delta \mathrm{KO}$ mice with a more substantial effect in mice with its combined KO with p38 $\gamma$ [60]. 
In colon cancer studies, $\mathrm{p} 38 \gamma$ and $\mathrm{p} 38 \delta$ global $\mathrm{KO}$ has no major impact on chronic inflammation but decreases acute inflammation in intestine tissues in response to DSS [59]. Moreover, mice with myeloid-specific p38 $\gamma$ and/or $\mathrm{p} 38 \delta \mathrm{KO}$ are resistant to diet-induced fatty liver, hepatic triglyceride, and glucose intolerance in association with defective migration of neutrophils to the damaged liver [76]. Analyses of global p $38 \gamma$ and/or $\mathrm{p} 38 \delta$ KO mice further showed that $\mathrm{p} 38 \delta$ and $\mathrm{p} 38 \gamma \mathrm{KO}$ differentially regulates $\mathrm{T}$ cell differentiation at different stages as compared with WT mice [61]. Separate studies showed that both myeloid-specific and global p38 $\delta$ KO decreased alveolar neutrophil accumulation and attenuated acute lung injury [77], whereas combined $\mathrm{p} 38 \gamma / \mathrm{p} 38 \delta$ myeloid-specific and global $\mathrm{KO}$ protects mice against fungal infection and inhibits leukocyte recruitment to infected kidneys [78]. These results together indicate that systemic $\mathrm{p} 38 \gamma$ and $\mathrm{p} 38 \delta$ activity and their signaling in immune cells (only KO data available in myeloid cells) are mostly pro-inflammatory and/or oncogenic (Fig. 1).

Recent genetic studies in mouse cancer models further showed that systemic and epithelial p38 $\gamma$ in gastrointestinal (GI) system is essential for tumorigenesis. Global p38 $\gamma$ and p38 $\delta \mathrm{KO}$ attenuates colitis-associated cancer (CAC) with their combined KO having more significant effects than either alone, indicating a cooperative oncogenic activity of systemic $\mathrm{p} 38 \gamma$ and $\mathrm{p} 38 \delta$ [59]. Moreover, IEC-specific p38 $\gamma \mathrm{KO}$ alone decreases pro-inflammatory cytokines (IL6 , IL-1 $\beta$ and TNF), inhibits the $\beta$-catenin/Wnt pathway in colonic tissues, and attenuates DSS-induced colitis and AOM/DSS-induced CAC [16]. Importantly, oral application of a p38 $\gamma$ selective pharmacological inhibitor pirfenidone (PFD) $[79,80]$ depends on epithelial p38 $\gamma$ to decrease $\mathrm{p} 38 \gamma$ phosphorylating its substrates and to reduce cytokine's levels in tumor tissues, and to inhibit tumorigenesis, suggesting a novel strategy to block colon tumorigenesis by targeting epithelial p38 [16]. p38 $\gamma$ was further shown to phosphorylate RB and to drive cell cycle progression, and hepatic $\mathrm{p} 38 \gamma \mathrm{KO}$ and systemic application of PFD both block diethyl nitrosamine (DEN)-induced liver tumorigenesis [62]. Our recent studies further showed that $\mathrm{p} 38 \gamma$ mediates KRAS oncogene signaling to activate the glycolytic pathway in pancreatic ductal cancer cells (Pdac) and that specific p38 $\gamma$ KO in pancreatic epithelial cells inhibits pancreatitis, reduces cytokine levels, and decreases pancreatic tumorigenesis in KPC mice [12]. Moreover, epithelial p38 $\gamma$ is required for PFD to suppress glycolytic pathways, to block pancreatic tumorigenesis in KPC mice, and to inhibit Pdac xenograft growth [12]. Together, these results demonstrate that epithelial $\mathrm{p} 38 \gamma$ is essential for colon, liver and pancreatic tumorigenesis and its pharmacological inhibitor PFD may have therapeutic potentials to block their development, growth, and progression (Fig. 1) (Tables 1,2).

Studies also showed that $\mathrm{p} 38 \delta$ is required for tumori- genesis in certain tissues. An early study showed that global $\mathrm{p} 38 \delta$ KO blocks DMBA/TPA-induced skin tumorigenesis [63]. Studies from Cuenda lab further showed that global $\mathrm{p} 38 \delta \mathrm{KO}$ alters expression of several cytokines in response to DSS [59]. Although combined global $\mathrm{p} 38 \gamma / \mathrm{p} 38 \delta$ KO appears to achieve more substantial effects in regulating cytokines and in inhibiting $\mathrm{CAC}$ than either alone in DSS/AOM mouse model, analyses of chimeric mice of WT with $\mathrm{p} 38 \gamma / \mathrm{p} 38 \delta^{-/-}$animals revealed a critical role of hematopoietic, but not epithelial, $\mathrm{p} 38 \gamma / \mathrm{p} 38 \delta$ in regulation of inflammatory mediators and immune cell recruitment [59]. A protective effect of global $\mathrm{p} 38 \delta \mathrm{KO}$ on DMBA/TPA-induced skin tumorigenesis was observed in association with decreased cytokines and chemokines in skin tissues, which are further enhanced in $\mathrm{p} 38 \gamma / \delta$ double KO mice [60]. A recent study further showed that conditional knockout of $\mathrm{p} 38 \delta$ in mammary epithelial cells decreases the viral oncogene PyMT-induced breast tumorigenesis in mice [64]. These results together indicate that systemic and epithelial $\mathrm{p} 38 \delta$, as in the case with $\mathrm{p} 38 \gamma$, is proinflammatory and oncogenic (Fig. 1) (Tables 1,2).

\section{Implications of cell/tissue-type dependent and isoform-specific effects of p38 MAPKs in inflammation and in inflammation-associated oncogenesis}

Mechanisms for cell/tissue-dependent and isoformspecific roles of $\mathrm{p} 38$ family proteins in inflammation and inflammation-associated oncogenesis are largely unknown. Although different p38 MAPK isoforms may regulate different sets of inflammation mediators and/or different groups of downstream molecules in response to different stimuli and/or in different cells/tissues, there is still a lack of experimental evidence to support this hypothesis. While it is difficult to systemically compare intrinsic activities of p38 family proteins in immune cells due to lack of genetic evidence, $\mathrm{p} 38 \alpha$ and p38 $\gamma$ in epithelial cells appear to be antagonistic. This effect has been observed at the level of protein, cell, and disease. At protein level, for example, p38 $\alpha$ and p38 $\gamma$ both phosphorylate the tumor suppressor $\mathrm{Rb}$ at different sites leading to an opposite effect on cellcycle progression. Specifically, $\mathrm{p} 38 \gamma$ phosphorylates $\mathrm{Rb}$ at $\mathrm{S} 807 / \mathrm{S} 811$ and stimulates G1/S transition [62], whereas p38 $\alpha$ phosphorylates $\mathrm{Rb}$ at $\mathrm{S} 429 / \mathrm{T} 252$ and slows cell-cycle progression [81]. Although $\mathrm{Rb}$ phosphorylation at these different sites is not known to be sufficient to trigger the opposite effect on cell-cycle progression, this mechanism may contribute to the tumor suppressor activity of $\mathrm{p} 38 \alpha$ and oncogenic activity of $\mathrm{p} 38 \gamma$. At cellular level, we showed an antagonizing effect of $\mathrm{p} 38 \alpha$ and $\mathrm{p} 38 \gamma$ in stress response and in KRAS transformation in which p $38 \alpha$ transfection directly depletes cellular $\mathrm{p} 38 \gamma$ protein by a ubiquitinationdependent mechanism [82] and that inhibition of p38 $\alpha$ activity with SB203580 increases p38 $\gamma$ protein levels [20]. At disease level, increased p-p38 $\alpha$ in pancreatic cancer tis- 
sues couples with increased patient's survival, indicating its tumor-suppressive activity [83], whereas upregulated p38 $\gamma$ in the same cancer predicts decreased patient survival, suggesting its oncogenic effect [12]. Thus, $\mathrm{p} 38 \gamma$ and $\mathrm{p} 38 \alpha$ can antagonize each other toward a protein substrate in stress or oncogene-induced cellular outcome and in clinical cancer development and progression. This cross-restrained activity of $\mathrm{p} 38 \alpha$ and $\mathrm{p} 38 \gamma$ could complicate therapeutic gain when their isoform-specific pharmacological inhibitors are used in systemic intervention. Please see recent outstanding reviews about p38 MAPKs and inhibitors [2,84].

Cell/tissue-specific effects of p38 family proteins will also have important implications for using their pharmacological inhibitors to regulate inflammation and inflammation-driven oncogenesis systemically. Although p38 $\alpha$ in immune cells is pro-inflammatory, application of its inhibitor SB203580 does not improve clinical symptoms of DSS-induced colitis in mice [41]. This might occur as an integration of its inhibition of pro-inflammatory p38 $\alpha$ activity in immune system and of its blockade of antiinflammatory effect of $\mathrm{p} 38 \alpha$ in intestinal epithelial cells (Fig. 1) [41]. These experimental results are consistent with a poor outcome of clinical trials using an oral p38 $\alpha$ inhibitor BIRB in the treatment of Crohn' disease [85]. On the other hand, p38 $\gamma$ activity in immune cells and in epithelial cells is both pro-inflammatory and oncogenic (Fig. 1) and its inhibitor PFD therefore showed a significant and consistent inhibitory effect on inflammation and inflammationassociated oncogenesis as observed in mouse models of colon, liver, and pancreatic cancer $[12,16,62]$. Considering of cell/tissue-dependent and isoform-specific effects of p 38 family proteins is therefore critical for development of effective small molecular p38 inhibitors against inflammation and inflammation-driven cancer in therapeutic intervention.

\section{Abbreviations}

AOM, azoxymethane; ATF2, activating transcription factor-2; BMDM, bone marrow-derived macrophages; DMBA, 12-dimethylbenz(a)anthracene; DCs, dendritic cells; DNFB, 2,4-dinitrofluorobenzene; DSS, dextran sulfate sodium; EGFR, epidermal growth factor receptor; ER, estrogen receptor $\alpha$; Hsp90, heat shock protein 90 alpha; IEC, intestinal epithelial cell; “-/-”, global deletion; KO, knockout; MAPKs, mitogen-activated protein kinases; MEFs, mouse embryonic fibroblasts; MEF2C, myocyte enhancer factor $2 \mathrm{C}$; MKK3 or 6, MAPK kinase 3 and/or 6; MMP9, matrix metalloproteinase; LPS, lipopolysaccharide; KPC, LSL-Kras ${ }^{G 12 D /+}:$ LSL-Trp53 $3^{R 172 H /+}$ : Pdx1Cre mice; MAPK, mitogen-activated protein kinase; $\mathrm{p} 38 \alpha$ MAPK, MAPK14; p38 $\beta$, MAPK11; p38 $\gamma$, MAPK12; $\mathrm{p} 38 \delta$, MAPK13; PRAK, p38 regulated/activated kinase; MK2, MAP kinase-activated protein kinase 2; MNK1, mitogen-activated protein kinase-interacting kinase 1; PFKFB3, phosphofructokinase-2/fructose-2,6bisphosphatase 3; PTPH1, protein tyrosine phosphatase
H1; PyMT, polyomavirus middle T antigen; TPA, $12-$ tetradecanoylphorbol-13-acetate; WT, wild-type.

\section{Author contributions}

JZQ, GC - concept development and manuscript writing; HX, XMQ — discussion of the manuscript and figure preparation.

\section{Ethics approval and consent to participate}

Not applicable.

\section{Acknowledgment}

We are very grateful to former Chen's lab members for their contributions to the research work.

\section{Funding}

This work has been supported by grants from NIH (R01 CA245977), VA (I01 BX005066), DOD (BC141898) and MCW Cancer Center (to GC).

\section{Conflict of interest}

The authors declare no conflict of interest. GC is serving as one of the Editorial Board members of this journal. We declare that GC had no involvement in the peer review of this article and has no access to information regarding its peer review. Full responsibility for the editorial process for this article was delegated to GP.

\section{References}

[1] Ono K, Han J. The p38 signal transduction pathway Activation and function. Cellular Signaling. 2000; 12: 1-13.

[2] Canovas B, Nebreda AR. Diversity and versatility of p38 kinase signaling in health and disease. Nature Reviews Molecular Cell Biology. 2021; 22: 346-366.

[3] Cuenda A, Sanz-Ezquerro J. p38 $\gamma$ and $\mathrm{p} 38 \delta$ : from spectators to key physiological players. Trends in Biochemical Sciences. 2017; 42: 431-42.

[4] Han J, Wu J, Silke J. An overview of mammalian p38 mitogenactivated protein kinases, central regulators of cell stress and receptor signaling. F1000 Faculty Reviews. 2020; 9: 653.

[5] Cuenda A, Rousseau S. P38 MAP-Kinases pathway regulation, function and role in human diseases. Biochimica Biophysica Acta (BBA) - Molecular Cell Research. 2007; 1773: 13581375.

[6] Chen G, Hitomi M, Han J, Stacey DW. The p38 pathway provides negative feedback to Ras proliferative signaling. Journal of Biological Chemistry. 2000; 275: 38973-80.

[7] Loesch M. The p38 MAPK stress pathway as a tumor suppressor or more? Frontiers in Bioscience. 2008; 13: 3581-3593.

[8] Qi X, Hou S, Lepp A, Li R, Basir Z, Lou Z, et al. Phosphorylation and Stabilization of Topoisomerase II $\alpha$ Protein by p38 $\gamma$ Mitogen-activated Protein Kinase Sensitize Breast Cancer Cells to its Poisons. Journal of Biological Chemistry. 2011; 286: 35883-35890.

[9] Qi X, Zhi H, Lepp A, Wang P, Huang J, Basir Z, et al. P38 $\gamma$ Mitogen-activated Protein Kinase (MAPK) Confers Breast Cancer Hormone Sensitivity by Switching Estrogen Receptor (ER) Signaling from Classical to Nonclassical Pathway via Stimulat- 
ing ER Phosphorylation and c-Jun Transcription. Journal of Biological Chemistry. 2012; 287: 14681-14691.

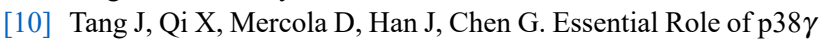
in K-Ras Transformation Independent of Phosphorylation. Journal of Biological Chemistry. 2005; 280: 23910-23917.

[11] Qi X, Wang F, Chen G. P38 Gamma MAPK. Encyclopedia of Signaling Molecules. 2018; 10: 3718-3727.

[12] Wang F, Qi X, Wertz R, Mortensen M, Hagen C, Evans J, et al. P38 $\gamma$ MAPK is Essential for Aerobic Glycolysis and Pancreatic Tumorigenesis. Cancer Research. 2020; 80: 3251-3264.

[13] Qi X, Xie C, Hou S, Li G, Yin N, Dong L, et al. Identification of a ternary protein-complex as a therapeutic target for K-Rasdependent colon cancer. Oncotarget. 2014; 5: 4269-4282.

[14] Rosenthal DT, Lyer H, Escudero S, Bao L, Wu Z, Ventura AC, et al. p38 $\gamma$ promotes breast cancer motility and metastasis through regulation of RhoC GTPase, cytoskeletal architecture, and a novel leading edge behavior. Cancer Research. 2011; 716338 49.

[15] Hou SW, Zhi H, Pohl N, Loesch M, Qi X, Li R, et al. PTPH1 dephosphorylates and cooperates with $\mathrm{p} 38 \gamma$ MAPK to increases Ras oncogenesis through PDZ-mediated interaction. Cancer Research. 2010; 70: 2901-10.

[16] Yin N, Qi X, Tsai S, Lu Y, Basir Z, Oshima K, et al. P38 $\gamma$ MAPK is required for inflammation-associated colon tumorigenesis. Oncogene. 2016; 35: 1039-1048.

[17] Hale KK, Trollinger D, Rihanek M, Manthey CL. Differential expression and activation of $\mathrm{p} 38$ mitogen-activated protein kinase alpha, beta, gamma, and delta in inflammatory cell lineages. Journal of Immunology. 1999; 162: 4246-52.

[18] Mukaro V, Quach A, Gahan ME, Boog B, Huang ZH, Gao Xea. Small tumor necrosis factor receptor biologics inhibit the tumor necrosis factor-p 38 signaling axis and inflammation. Nature Communications. 2018; 9: 1635.

[19] Korb A, Tohidast-Akrad M, Cetin E, Axmann R, Smolen J, Schett G. Differential tissue expression and activation of $\mathrm{p} 38$ MAPK $\alpha, \beta, \gamma$, and $\delta$ isoforms in rheumatoid arthritis. Arthritis \& Rheumatism. 2006; 54: 2745-2756.

[20] Loesch M, Zhi H, Hou S, Qi X, Li R, Basir Z, et al. P38 $\gamma$ MAPK Cooperates with c-Jun in trans-Activating Matrix Metalloproteinase 9. Journal of Biological Chemistry. 2010; 285: 1514915158.

[21] Qi X, Yin N, Ma S, Lepp A, Tang J, Jing W, et al. P38 $\gamma$ MAPK is a Therapeutic Target for Triple-Negative Breast Cancer by Stimulation of Cancer Stem-Like Cell Expansion. STEM CELLS. 2015; 33: 2738-2747.

[22] Yin N, Lepp A, Ji Y, Mortensen M, Hou S, Qi X, et al. The KRas effector $\mathrm{p} 38 \gamma$ MAPK confers intrinsic resistance to tyrosine kinase inhibitors by stimulating EGFR transcription and EGFR dephosphorylation. Journal of Biological Chemistry. 2017; 292: 15070-15079.

[23] Remy G, Risco AM, Iñesta-Vaquera FA, González-Terán B, Sabio G, Davis RJ, et al. Differential activation of p38MAPK isoforms by MKK6 and MKK3. Cellular Signalling. 2010; 22: 660-667.

[24] Hou S, Lepp A, Chen G. p38 gamma MAP kinase UCSD-Nature Molecular Pages. 2010; doi:1038/mp.a001720.01.

[25] Sabio G, Reuver S, Feijoo C, Hasegawa M, Thomas GM, Centeno F, et al. Stress- and mitogen-induced phosphorylation of the synapse-associated protein SAP90/PSD-95 by activation of SAPK3/p38 $\gamma$ and ERK1/ERK2. Biochemical Journal. 2004; 380: $19-30$.

[26] Hou S, Padmanaban S, Qi X, Leep A, Mirza S, Chen G. p38 $\gamma$ MAPK signals through phosphorylating its phosphatase PTPH1 in regulating Ras oncogenesis and stress response. Journal of Biological Chemistry. 2012; 287: 27895-27905.

[27] Ma S, Yin N, Qi X, Pfister SL, Zhang M, Ma R, et al. Tyro- sine dephosphorylation enhances the therapeutic target activity of epidermal growth factor receptor (EGFR) by disrupting its interaction with estrogen receptor (ER) Oncotarget. 2015; 6: 13320-13333.

[28] Qi X, Wang F, Mortensen M, Wertz R, Chen G. Targeting an oncogenic kinase/phosphatase signaling network for cancer therapy. Acta Pharmaceutica Sinica B. 2018; 8: 511-517.

[29] Pruitt K, Pruitt WM, Bilter GK, Westwick JK, Der CJ. Rafindependent Deregulation of p38 and JNK Mitogen-activated Protein Kinases are Critical for Ras Transformation. Journal of Biological Chemistry. 2002; 277: 31808-31817.

[30] Awad MM, Enslen H, Boylan JM, Davis RJ, Gruppuso PA. Growth Regulation via p38 Mitogen-activated Protein Kinase in Developing Liver. Journal of Biological Chemistry. 2000; 275: 38716-38721.

[31] Sun P, Yoshizuka N, New L, Moser BA, Li Y, Liao R, et al. PRAK is Essential for ras-Induced Senescence and Tumor Suppression. Cell. 2007; 128: 295-308.

[32] Zhang R, Murakami S, Coustry F, Wang Y, de Crombrugghe B. Constitutive activation of MKK6 in chondrocytes of transgenic mice inhibits proliferation and delays endochondral bone formation. Proceedings of the National Academy of Sciences. 2007; 103: 365-370.

[33] Wuestefeld T, Pesic M, Rudalska R, Dauch D, Longerich T, Kang T, et al. A Direct in Vivo RNAi Screen Identifies MKK4 as a Key Regulator of Liver Regeneration. Cell. 2013; 153: 389401.

[34] Brancho D, Tanaka N, Jaeschke A, Ventura J, Kelkar N, Tanaka Y, et al. Mechanism of $\mathrm{p} 38$ MAP kinase activation in vivo. Genes \& Development. 2003; 17: 1969-1978.

[35] Kobayashi Y, Qi X, Chen G. MK2 Regulates Ras Oncogenesis through Stimulating ROS Production. Genes \& Cancer. 2012; 3: $521-530$.

[36] Suarez-Lopez L, Sriram G, Kong YW, Morandell S, Merrick KA, Hernandez Y, et al. MK2 contributes to tumor progression by promoting M2 macrophage polarization and tumor angiogenesis. Proceedings of the National Academy of Sciences. 2018; 115: E4236-E4244.

[37] Ventura JJ, Tenbaum S, Perdiguero E, Huth M, Guerra C, Barbacid M, et al. p38 $\alpha$ MAP kinase is essential in lung stem and progenictor cell proliferation and differentiation. Nature Genetics. 2007; 39: 750-758.

[38] Dolado I, Swat A, Ajenjo N, De Vita G, Cuadrado A, Nebreda AR. P38 $\alpha$ MAP Kinase as a Sensor of Reactive Oxygen Species in Tumorigenesis. Cancer Cell. 2007; 11: 191-205.

[39] Batlle R, Andrés E, Gonzalez L, Llonch E, Igea A, Gutierrez-Prat N, et al. Regulation of tumor angiogenesis and mesenchymal-endothelial transition by $\mathrm{p} 38 \alpha$ through TGF- $\beta$ and JNK signaling. Nature Communications. 2019; 10: 3071 .

[40] Hui L, Bakiri L, Mairhorfer A, Schweifer N, Haslinger C, Kenner $\mathrm{L}$, et al. $\mathrm{P} 38 \alpha$ suppresses normal and cancer cell proliferation by antagonizing the JNK-c-Jun pathway. Nature Genetics. 2007; 39: 741-749.

[41] Otsuka M, Kang YJ, Ren J, Jiang H, Wang Y, Omata M, et al. Distinct Effects of p38 $\alpha$ Deletion in Myeloid Lineage and Gut Epithelia in Mouse Models of Inflammatory Bowel Disease. Gastroenterology. 2010; 138: 1255-1265.

[42] Youssif C, Cubillos-Rojas, Comalade M, LIonch E, Perna C, Djouder Nea. Myeloid p38 $\alpha$ signaling promotes intestinal IGF-1 production and inflammation-associated tumorigenesis. EMBO Molecular Medicine. 2018; 10: e8403.

[43] Wakeman D, Schneider JE, Liu J, Wandu WS, Erwin CR, Guo $\mathrm{J}$, et al. Deletion of $\mathrm{p} 38$-alpha mitogen-activated protein kinase within the intestinal epithelium promotes colon tumorigenesis. Surgery. 2012; 152: 286-293. 
[44] Gupta J, Barantes IB, Igea A, Sakellariou S, Pateras I, Gorgoulis VGea. Dual function of $\mathrm{p} 38 \alpha$ MAPK in colon cancer: suppression of colities-associated tumor initiation but requirement for cancer cell survival. Cancer Cell. 2014; 25: 484-550.

[45] Vitos-Faleato J, Real SM, Gutierrez-Prat N, Villanueva A, Llonch E, Drosten M, et al. Requirement for epithelial $\mathrm{p} 38 \alpha$ in KRAS-driven lung tumor progression. Proceedings of the National Academy of Sciences. 2020; 117: 2588-2596.

[46] Kim C, Sano Y, Todorova K, Carlson BA, Arpa L, Celada A, et $a l$. The kinase $\mathrm{p} 38 \alpha$ serves cell type-specific inflammatory functions in skin injury and cooridinates pro- and anti-inflammatory gene expression. Nature Immunology. 2008; 9: 1019-1027.

[47] Sano Y, Park JM. Loss of epidermal p38 $\alpha$ signaling prevents UVR-induced inflammation via acute and chronic mechanisms. Journal of Investigative Dermatology. 2014; 134: 2231-40.

[48] Ritprajak P, Hayakawa M, Sano Y, Otsu K, Park JM. Cell type-specific targeting dissociates the therapeutic from the adverse effects of protein kinase inhibition in allergic skin disease. Proceedings of the National Academy of Sciences. 2012; 109: 9089-9094.

[49] Sakurai T, Kudo M, Umemura A, He G, Elsharkawy AM, Seki E, et al. p38 $\alpha$ inhibits liver fibrogenesis and consequent hepatocarcinogenesis by curtailing accumulation reactive oxygen species. Cancer Research. 2012; 73: 215-224.

[50] Gurusamy D, Henning AN, Yamamoto TN, Yu Z, Zacharakis N, Krishna S, et al. Multi-phenotype CRISPR-Cas9 Screen Identifies p38 Kinase as a Target for Adoptive Immunotherapies. Cancer Cell. 2020; 37: 818-833.e9.

[51] Gui J, Zahedi F, Ortiz A, Cho C, Katlinski KV, Alicea-Torres Kea. Activation of $\mathrm{p} 38 \alpha$ stress-activated proein kinase drives the formation of the pre-metastatic niche in the lungs. Nature Cancer. 2020; 1: 603-609.

[52] Brichkina A, Bertero T, Loh HM, Nguyen NTM, Emelyanov A, Rigade $\mathrm{S}$, et al. P38MAPK builds a hyaluronan cancer niche to drive lung tumorigenesis. Genes \& Development. 2016; 30 : $2623-2636$

[53] Huang J, Nguyen-McCarty M, Hexner EO, Danet-Desnoyers G, Klein PS. Maintenance of hematopoietic stem cells through regulation of Wnt and mTOR pathways. Nature Medicine. 2012; 18: $1778-1785$.

[54] Zheng T, Zhang B, Chen C, Ma J, Meng D, Huang J, et al. Protein kinase $\mathrm{p} 38 \alpha$ signaling in dendritic cells regulates colon inflammation and tumorigenesis. Proceedings of the National Academy of Sciences. 2018; 115: E12313-E12322.

[55] Kang YJ, Chen J, Otsuka. M., Mols J, Ren S, Wang $\mathrm{Y}$, et al. Macrophage deletion of $\mathrm{p} 38 \alpha$ partially impairs lipopolysaccharide-induced cellular activation. Journal of Immunology. 2008; 180: 5075-5082.

[56] Raza A, Crothers JW, McGill MM, Mawe GM, Teuscher C, Krementsov DN. Anti-inflammatory roles of p38 $\alpha$ MAPK in macrophages are context dependent and require IL-10. Journal of Leukocyte Biology. 2017; 102: 1-9.

[57] Noubade R, Krementsov DN, del Rio R, Thornton T, Nagaleekar $\mathrm{V}$, Saligrama N, et al. Activation of $\mathrm{p} 38$ MAPK in CD4 T cells controls IL-17 production and autoimmune encephalomyelitis. Blood. 2011; 118: 3290-3300.

[58] Risco A, del Fresno C, Mambol A, Alsina-Beauchamp D, MacKenzie KF, Yang H-, et al. P38 and p38 kinases regulate the Toll-like receptor 4 (TLR4)-induced cytokine production by controlling ERK1/2 protein kinase pathway activation. Proceedings of the National Academy of Sciences. 2012; 109: 1120011205.

[59] del Reino P, Alsina-Beauchamp D, Escós A, Cerezo-Guisado MI, Risco A, Aparicio N, et al. Pro-Oncogenic Role of Alternative p38 Mitogen-Activated Protein Kinases p38 $\gamma$ and p38 Linking Inflammation and Cancer in Colitis-Associated Colon
Cancer. Cancer Research. 2014; 74: 6150-6160.

[60] Zur R, Garcia-Ibanez L, Nunez-Buiza A, Aparicio N, Liappas $\mathrm{G}$, Escós A, et al. Combined deletion of $\mathrm{p} 38 \gamma$ and $\mathrm{p} 38 \delta$ reduces skin inflammation and protects from carcinogenesis. Oncotarget. 2015; 6: 12920-12935.

[61] Risco A., Martin-Serrano M, Barber DF, Cuenda A. p38 $\gamma$ and p38 Are Involved in T Lymphocyte Development. Frontiers in Immunology. 2018; 9: 65.

[62] Tomás-Loba A, Manieri E, González-Terán B, Mora A, LeivaVega L, Santamans AM, et al. P38 $\gamma$ is essential for cell cycle progression and liver tumorigenesis. Nature. 2019; 568: $557-$ 560.

[63] Schindler EM, Hindes A, Gribben EL, Burns CJ, Yin Y, Lin M, et al. P38 Mitogen-Activated Protein Kinase is Essential for Skin Tumor Development in Mice. Cancer Research. 2009; 69: 4648-4655.

[64] Wada M, Canals D, Adada M, Coant N, Salama MF, Helke KL, et al. P38 delta MAPK promotes breast cancer progression and lung metastasis by enhancing cell proliferation and cell detachment. Oncogene. 2017; 36: 6649-6657.

[65] Tamura K, Sudo T, Senftleben U, Dadak AM, Johnson R, Karin M. Requirement for $\mathrm{p} 38 \alpha$ in Erythropoietin Expression. Cell. 2000; 102: 221-231.

[66] Adams RH, Porras A, Alonso G, Jones M, Vintersten K, Panelli $\mathrm{S}$, et al. Essential Role of $\mathrm{p} 38 \alpha$ MAP Kinase in Placental but not Embryonic Cardiovascular Development. Molecular Cell. 2000; 6: 109-116.

[67] Huang G, Wang Y, Vogel P, Kanneganti T, Otsu K, Chi H. Signaling via the kinase $\mathrm{p} 38 \alpha$ programs dendritic cells to drive TH17 differentiation and autoimmune inflammation. Nature Immunology. 2012; 13: 152-161.

[68] Chan JD, Beavis PA, Darcy PK. P38 Kinase: a Key Target for Driving Potent $\mathrm{T}$ Cells for Adoptive Immunotherapy. Cancer Cell. 2020; 37: 756-758.

[69] Maik-Rachline G, Zehoral E, Hanoch T, Bleins J, Seger R. The nuclear translocation of the kinase $\mathrm{p} 38$ and JNK promotes inflammation-induced cancer. Science Signaling. 2018; 11: eaao3428.

[70] Alspach E, Flanagan KC, Luo X, Ruhland MK, Huang H, Pazolli $\mathrm{E}$, et al. P38MAPK Plays a Crucial Role in Stromal-Mediated Tumorigenesis. Cancer Discovery. 2014; 4: 716-729.

[71] TIAN X, TRAUB B, XIE X, ZHOU S, HENNE-BRUNS D, KNIPPSCHILD U, et al. Opposing Oncogenic Functions of p38 Mitogen-activated Protein Kinase Alpha and Beta in Human Pancreatic Cancer Cells. Anticancer Research. 2020; 40: 55455556.

[72] Ferrari G, Terushkin V, Wolff MJ, Zhang X, Valacca C, Poggio Pea. TGF- $\beta 1$ endothelial cell apoptosis by shifting VEGF activation of $\mathrm{p} 38 \mathrm{MAPK}$ from the prosurvival $\mathrm{p} 38 \beta$ to proapoptotic p38 $\alpha$. Molecular Cancer Research. 2012; 10: 605-14.

[73] Beardmore VA, Hinton HJ, Eftychi C, Apostolaki M, Armaka $\mathrm{M}$, Darragh J, et al. Generation and Characterization of $\mathrm{p} 38 \beta$ (MAPK11) Gene-Targeted Mice. Molecular and Cellular Biology. 2005; 25: 10454-10464.

[74] Xu W, Liu R, Dai Y, Hong S, Dong H, Wang H. The Role of p38 $\gamma$ in Cancer: from review to outlook. International Journal of Biological Sciences. 2021; 17: 4036-4046.

[75] Sabio G, Arthur JSC, Kuma Y, Peggie M, Carr J, Murray-Tait V, et al. P38 $\gamma$ regulates the localisation of SAP97 in the cytoskeleton by modulating its interaction with GKAP. the EMBO Journal. 2005; 24: 1134-1145.

[76] González-Terán B, Matesanz N, Nikolic I, Verdugo MA, Sreeramkumar V, Hernández-Cosido L, et al. $\mathrm{P} 38 \gamma$ and $\mathrm{p} 38 \delta$ reprogram liver metabolism by modulating neutrophil infiltration. the EMBO Journal. 2016; 35: 536-552.

[77] Ittner A, Block H, Reichel CA, Varjosalo M, Gehart H, Sumara 
$\mathrm{G}$, et al. Regulation of PTEN activity by $\mathrm{p} 38 \delta$-PKD1 signaling in neutrophils confers inflammatory responses in the lung. Journal of Experimental Medicine. 2012; 209: 2229-2246.

[78] Alsina-Beauchamp D, Escós A, Fajardo P, González-Romero D, Díaz-Mora E, Risco A, et al. Myeloid cell deficiency of $\mathrm{p} 38 \mathrm{\gamma} / \mathrm{p} 38 \delta$ protects against candidiasis and regulates antifungal immunity. EMBO Molecular Medicine. 2018; 10.

[79] Ozes O, Blatt LM, Seiwert SD. Use of pirfenidone in therapeutic regimens. United States Patent-US 7,407,973 B2 2008; Aug. 5 th: $1-46$.

[80] Richeldi L, Yasothan U, Kirkpatrick P. Pirfenidone. Nature Reviews Drug Discovery. 2011; 10: 489-490.

[81] Gubern A, Joaquin M, Marquès M, Maseres P, Garcia-Garcia J, Amat R, et al. The N-Terminal Phosphorylation of RB by $\mathrm{p} 38$ Bypasses its Inactivation by CDKs and Prevents Proliferation in Cancer Cells. Molecular Cell. 2016; 64: 25-36.
[82] Qi X, Pohl NM, Loesch M, Hou S, Li R, Qin J, et al. P38 $\alpha$ Antagonizes p38 $\gamma$ Activity through c-Jun-dependent Ubiquitinproteasome Pathways in Regulating Ras Transformation and Stress Response. Journal of Biological Chemistry. 2007; 282: 31398-31408.

[83] Alam MS, Gaida MM, Bergmann F, Lasitschka F, Giese T, Giese NA, et al. Selective inhibition of the p38 alternative activation pathway in infiltrating $\mathrm{T}$ cells inhibits pancreatic cancer progression. Nature Medicine. 2015; 21: 1337-1343.

[84] Machado TR, Machado TR, Pascutti PG. The p38 MAPK Inhibitors and their Role in Inflammatory Diseases. ChemistrySelect. 2021; 6: 5729-5742.

[85] Schreiber S, Feagan B, D’Haens Gea. Oral p38 mitogenactivated protein kinase inhibition with BIRB 796 for active Crohn' disease: a randomized, double-blind, placebo-controlled trial. Clinical Gastroenterology Hapatology. 2006; 4: 325-334. 